\title{
Numerical investigation on fin-tube three-fluid heat exchanger for hybrid source HVAC\&R systems
}

Hainan Zhang ${ }^{\mathrm{a}, \mathrm{b}, \mathrm{c}}$, Shuangquan Shao ${ }^{\mathrm{a}, \mathrm{b}, *}$, Hongbo $\mathrm{Xu}^{\mathrm{a}, \mathrm{b}}$, Huiming Zou ${ }^{\mathrm{a}, \mathrm{b}}$, Mingsheng Tang $^{\mathrm{a}, \mathrm{b}}$, Changqing Tian ${ }^{\mathrm{a}, \mathrm{b}}$

a Key Laboratory of Cryogenics, Technical Institute of Physics and Chemistry, Chinese Academy of Sciences, 29 Zhongguancun East Road, Beijing 100190, PR China

b Beijing Key Laboratory of Thermal Science and Technology, Technical Institute of Physics and Chemistry, Chinese Academy of Sciences, 29 Zhongguancun East Road, Beijing 100190, PR China

c University of Chinese Academy of Sciences, No.19A Yuquan Road, 100049, Beijing, PR China

* Corresponding author. Tel.: +86 1082543433. E-mail address: shaoshq@mail.ipc.ac.cn (S.Q. Shao)

Abstract: The energy consumption of HVAC\&R systems is increasing rapidly and application of hybrid source systems is an alternative solution. Utilizing three-fluid heat exchanger in hybrid source HVAC\&R system can make the system more compact in construction, higher in thermal efficiency and lower in reliability risk. In this paper, a simulation model of a fin-tube three-fluid heat exchanger is built with distributed-parameter method and validated by experimental data. Based on the demand of a new type of hybrid source system, the optimal circuit arrangement type and tube diameter are achieved. The heat transfer rates of the three fluids under different working conditions are investigated. The results also show that to ensure that cold fluid 1 is superheated in the outlet for the stable running of the system, flow rate 
and inlet pressure of the hot fluid and air inlet temperature should be higher than certain values, while flow rate and inlet pressure of cold fluid 1 should be lower than certain values. Air flow rate can be adjusted freely without range limit. This paper will help the design of fin-tube three-fluid heat exchanger and promote its application in HVAC\&R systems.

Key words: HVAC\&R, three-fluid heat exchanger, heat pump, air conditioning, simulation

\begin{tabular}{|c|c|}
\hline Nomenclatures & \\
\hline$A_{1}, A_{2}$ & areas as illustrated in Fig. $2, \mathrm{~m}^{2}$ \\
\hline$c_{\mathrm{p}}$ & specific heat, $\mathrm{J} \mathrm{kg} \mathrm{K}^{-1}$ \\
\hline$G$ & mass flux, $\mathrm{kg} \mathrm{m}^{-2} \mathrm{~s}^{-1}$ \\
\hline$g$ & acceleration of gravity, $\mathrm{m} \mathrm{s}^{-2}$ \\
\hline$h_{\mathrm{fg}}$ & liquid-vapor latent heat, $\mathrm{J} \mathrm{kg}^{-1}$ \\
\hline$\dot{m}$ & mass flow rate, $\mathrm{kg} \mathrm{s}^{-1}$ \\
\hline$p$ & pressure, $\mathrm{Pa}$ \\
\hline$Q$ & heat transfer rate, $\mathrm{W}$ \\
\hline$T$ & temperature, $\mathrm{K}$ \\
\hline$U_{1}, U_{2}$ & overall heat transfer coefficient, $\mathrm{W} \mathrm{K}^{-1} \mathrm{~m}^{-2}$ \\
\hline$\dot{v}$ & volume flow rate, $\mathrm{m}^{3} \mathrm{~s}^{-1}$ \\
\hline$x$ & vapor quality \\
\hline$z$ & height, $\mathrm{m}$ \\
\hline$\Delta p$ & pressure drop, $\mathrm{Pa}$ \\
\hline$\Delta v$ & change of specific volume, $\mathrm{m}^{3} \mathrm{~kg}^{-1}$ \\
\hline$\rho$ & density, $\mathrm{kg} \mathrm{m}^{-3}$ \\
\hline
\end{tabular}




\begin{tabular}{|ll|}
\hline Subscripts & acceleration \\
ave & average \\
cal & calculated \\
c1 & cold fluid 1 \\
c2 & cold fluid 2 \\
f & friction \\
g & gravity \\
h & hot fluid \\
in & inlet \\
out & outlet \\
sat & saturation \\
sup & supposed \\
TP & two-phase \\
Abbreviations & \\
\hline
\end{tabular}

\section{Introduction}

Nowadays, Heating, Ventilation, Air Conditioning and Refrigeration (HVAC\&R) systems are used in a large diversity of activities. The energy consumption of HVAC\&R systems accounts for more than $35 \%$ of the total electrical energy consumed in the US [1]. Utilization of renewable energy is the most effective method to reduce this consumption. However, many kinds of renewable energy are not stable and adequate enough to be used as the only energy source [2-5]. Hybrid source 
HVAC\&R system is an ideal solution to achieve continuous working and shows great application potential, representative examples are hybrid source heat pumps [6-9] and hybrid source free cooling systems [10-12]

In order to use more than one energy sources, most hybrid source systems use two or more heat exchangers in series or parallel connection to transfer heat between three or more fluids. This kind of system has energy-saving effect while it still has the following shortcomings:

(1) To achieve the utilization of multi-source, series or parallel connection of heat exchangers exists, which makes the system complex in structure [13].

(2) Fluid flow inside the system is difficult to forecast due to series and parallel connection of heat exchangers, which affects the stable and efficient working [14].

(3) Solenoid valves are needed for switching between working modes [15], which brings reliability risk.

As we know, three-fluid heat exchanger is a type of heat exchangers which can transfer heat synchronously between three fluids. It has been used in cryogenics, aerospace and chemical industries [16,17]. The application of three-fluid heat exchangers in these fields makes the equipments more compact in construction, higher in thermal efficiency [18] and lower in reliability risk [19]. However, few three-fluid heat exchangers have been used in HVAC\&R systems until now, while they show great potential in this field to overcome the above shortcomings.

Analysis of three-fluid heat exchanger was first conducted by Morley in 1933 [20]. Ever since many researchers developed it further. Analytical solution was obtained for special cases [21]. Finite element models were developed for some types of three-fluid heat exchangers, including co-current parallel flow [22,23], countercurrent parallel flow [17,22-25] and cross parallel flow [26-28]. Integral-mean 
temperature difference model has also been developed to simplify the simulation of three-fluid heat exchangers [18]. Dimensionless design parameters that can be used to evaluate the performance of three-fluid heat exchangers have been studied $[16,29,30]$. Exergy theory and entropy generation number have been applied to describe and analyse the performance of three-fluid heat exchangers from irreversible thermodynamic theory [24,25]. However, all of the above studies only deal with heat transfer without phase change and do not include three-fluid heat exchangers that can be used for HVAC\&R systems, in which two-phase fluid and air often exist.

A new type of three-fluid heat exchanger, fin-tube three-fluid heat exchanger, was proposed recently [31] as shown in Fig. 1. Its tube circuit consists of an inner tube, an outer tube and fins outside the outer tube. This type of heat exchanger can be used to achieve the heat transfer between air and two in-tube fluids. Therefore, it is suitable for application in hybrid source HVAC\&R systems such as hybrid source heat pumps and free cooling systems. However, few studies have been conducted on this new type heat exchanger until now.

To overcome the above short comings of existing hybrid source systems, the authors proposed a new type of hybrid source free cooling system utilizing fin-tube three-fluid heat exchanger, called integrated system of mechanical refrigeration and thermosyphon (ISMT) [32]. The schematic diagram of the system is shown in Fig. 2. It includes two circulation loops: a refrigeration loop and a thermosyphon loop. A three-fluid heat exchanger is used to connect the two loops. The fluid in the thermosyphon loop can transfer heat with the other two fluids to achieve the simultaneous utilization of mechanical cooling source and free cooling source.

For better use of fin-tube three-fluid heat exchanger, performance investigation is essential. This paper focuses on performance investigation of fin-tube three-fluid 
heat exchanger for application in ISMT, a new type hybrid source HVAC\&R system. A simulation model of the fin-tube three-fluid heat exchanger is built with distributedparameter method and validated by experimental data. With the validated simulation model, the performance and applicability of different structures and working conditions in the ISMT are investigated. This paper will help the design of fin-tube three-fluid heat exchanger and promote its application in HVAC\&R systems.

\section{Model of Three-fluid Heat Exchanger}

The flow arrangement of the fin-tube three-fluid heat exchanger in the ISMT is shown in Fig. 3. Cold fluid 1 (working fluid of the refrigeration loop) flows and evaporates in the inner tube. Cold fluid 2 (air) flows through the fins outside the outer tube. The hot fluid (working fluid of the thermosyphon loop) flows and condenses in the annular space between the inner and outer tube, cooled by the other two fluids.

The numerical model is developed with distributed-parameter method, dividing the tube circuit into elements along the axial direction as shown in Fig. 3. Each tube is divided into 30 elements. The flow chart of three-fluid heat exchanger simulation is shown in Fig. 4. The inlet conditions of the hot fluid and cold fluid 1 in one tube are the outlet conditions of the former tube in the flow circuit. The inlet air (cold fluid 2) conditions of each element in the second row along the airflow direction are the outlet conditions of the element in the same position in first row. Compared with two-fluid heat exchangers, two heat transfer rates are needed to be supposed and two iterations are needed in each element. The heat transfer rate of the two sides in an element can be calculated as:

$$
\begin{aligned}
& Q_{\mathrm{c} 1}=U_{1} A_{1}\left(T_{\mathrm{h}, \mathrm{ave}}-T_{\mathrm{c} 1, \mathrm{ave}}\right) \\
& Q_{\mathrm{c} 2}=U_{2} A_{2}\left(T_{\mathrm{h}, \mathrm{ave}}-T_{\mathrm{c} 2 \text {,ave }}\right)
\end{aligned}
$$

where, $Q_{\mathrm{c} 1}$ and $Q_{\mathrm{c} 2}$ are the heat transfer rate in an element of cold fuild 1 and cold 
fluid 2 (air), respectively, $\mathrm{W} ; T_{\mathrm{h} \text {,ave }}, T_{\mathrm{c} 1 \text {,ave }}, T_{\mathrm{c} 2 \text {,ave }}$ are the average temperature in the element of the hot fluid, cold fluid 1 and cold fluid 2, respectively, $\mathrm{K} ; U_{1} A_{1}$ and $U_{2} A_{2}$ are the overall heat conductance in an element as illustrated in Fig. $3, \mathrm{~W} \mathrm{~K}^{-1}$. The heat transfer rate of the hot fluid is also the total heat transfer rate of the element:

$$
Q_{\mathrm{h}}=Q_{\mathrm{c} 1}+Q_{\mathrm{c} 2}
$$

The two-phase pressure drop in an element is calculated as:

$$
\Delta p=\Delta p_{\mathrm{f}}+\Delta p_{\mathrm{a}}+\Delta p_{\mathrm{g}}=\Delta p_{\mathrm{f}}+G^{2} \Delta v+g \rho_{\mathrm{TP}} z
$$

where, $\Delta p_{\mathrm{f}}, \Delta p_{\mathrm{a}}, \Delta p_{\mathrm{g}}$ are the fiction, acceleration and gravity pressure drop, respectively, $\mathrm{Pa} ; G$ is the mass flux, $\mathrm{kg} \mathrm{m}^{-2} \mathrm{~s}^{-1} ; \Delta v$ is the change of specific volume, $\mathrm{m}^{3} \mathrm{~kg}^{-1} ; \rho_{\mathrm{TP}}$ is the density of two-phase fluid, $\mathrm{kg} \mathrm{m}^{-3} ; z$ is the height difference of the inlet and outlet of the element, $\mathrm{m}$; $g$ is the acceleration of gravity, $\mathrm{m} \mathrm{s}^{-2}$.

The heat transfer and pressure drop correlations are shown in Table 1. The refrigerant thermodynamic properties are fitted by the data provided by Refprop 8 [39], and the modelling code is developed based on VC6.0.

In order to validate the accuracy of the model, the performance of the three-fluid heat exchanger was also investigated by experiments. The experiments were carried out in a test room of air conditioners. The airside conditions were controlled by the air handling unit of the test room, and measured by a test chamber of enthalpy difference. The flow conditions inside the tube were measured by transducers of pressure, temperature and flow rate in the inlet and outlet of the heat exchanger. The front velocity of the airflow is around $1.1 \mathrm{~m}^{3} \mathrm{~s}^{-1}$ and the temperature is $12 \sim 22{ }^{\circ} \mathrm{C}$. The flow rates of the hot fluid and cold fluid 1 are $0.03 \sim 0.10 \mathrm{~kg} \mathrm{~s}^{-1}$ and $0.02 \sim 0.04 \mathrm{~kg} \mathrm{~s}^{-1}$, respectively. The calculated total heat transfer rate (heat transfer rate of the hot fluid) is compared to experimental results of the three-fluid heat exchanger as shown in Fig. 5. The calculated values agree well with the experimental ones with deviations of $-10 \%$ 
and $+6 \%$.

\section{Results and Discussions}

In this paper, the applicability of different structures of fin-tube three-fluid heat exchanger is studied firstly to choose an appropriate structure for the system. Then, the inlet fluid conditions are varied to investigate the performance of the heat exchanger in various working conditions of the system.

\subsection{Performance of different structures}

The outlet of cold fluid 1 connects the inlet of the compressor in the refrigeration loop (refer to Fig. 2). Therefore, cold fluid 1 in the outlet must be superheated to avoid liquid hammer, which means liquid fluid entering the compressor and will damage its valve plate. In this section, the required outlet condition of cold fluid 1 is given to choose between different structures. This typical working condition is shown in Table 2.

Three different circuit arrangement types of fin-tube three-fluid heat exchanger are shown in Fig. 6. All of the three types have two rows and 28 inner and outer tubes in each row while circuit numbers are different. In type A, there are 28 parallel circuits of cold fluid 1 and hot fluid, that is, one circuit of cold fluid 1 connects one circuit of the hot fluid. In type B and C, one circuit of cold fluid 1 connects four and seven circuits of the hot fluid, respectively, reducing the circuit number of cold fluid 1 compared to Type A. The geometric parameters of the three types are the same and shown in Table 3.

The total heat transfer rates (heat transfer rates of the hot fluid) of different arrangement types and inner tube diameters are shown in Fig. 7. The heat transfer rate of type A is relatively small because it has more circuits of cold fluid 1 therefore the flow rate in one single circuit is lower. However, it can be seen that less circuits do 
not always mean higher heat transfer rate. The heat transfer rate of type $\mathrm{C}$ is lower than that of type B. This is mainly due to the higher pressure drop of cold fluid 1 in Type $\mathrm{C}$ so that when the outlet condition is the same, the average evaporation pressure of cold fluid 1 is higher. Therefore, the temperature difference between the hot fluid and cold fluid 1 in Type $\mathrm{C}$ is smaller than Type B so the heat transfer rate is smaller. The heat transfer rate increases with increasing inner tube diameter for smaller flow area and higher velocity of the hot fluid. While, the inner tube diameter should not be too close to the outer tube diameter, which will bring higher pressure drop of the hot fluid side and difficulty in manufacture. Considering these factors, type $\mathrm{B}$ is chosen for the system and the inner tube outside diameter is fixed at $6.0 \mathrm{~mm}$.

\subsection{Performance under different working conditions}

With the optimal structure achieved above, the performance under different inlet conditions is investigated in this section. The inlet conditions are those often appear in the ISMT, which are shown in Table 4. When one inlet parameter is varied in the variation range to investigate its effect on the performance, other inlet parameters keep the base line values in Table 4 .

The heat transfer rate and outlet temperature varied with the flow rate of the hot fluid are shown in Fig. 8 and Fig. 9, respectively. The heat transfer rates of the three fluids all increase with increasing flow rate of the hot fluid, because higher flow rate enhances the heat transfer between the hot fluid and other fluids. When cold fluid 1 is superheated in the outlet $\left(T_{\mathrm{c} 1 \text {,out }}>T_{\mathrm{c} 1 \text {,sat }}, T_{\mathrm{c} 1 \text {,sat }}\right.$ is the saturation temperature corresponding to the outlet pressure of cold fluid 1), this increase turns slower. As mentioned above, cold fluid 1 in the outlet must be superheated to avoid liquid hammer of the compressor in the ISMT. When the flow rate of the hot fluid is relatively low, cold fluid 1 in the outlet is in two-phase state, as shown in Fig. 9. 
Therefore, flow rate of the hot fluid in the system should be higher than a certain value, which is $0.044 \mathrm{~kg} \mathrm{~s}^{-1}$ in this study.

The heat transfer rate and outlet temperature varied with the flow rate of cold fluid 1 are shown in Fig. 10 and Fig. 11, respectively. The heat transfer rates of the hot fluid and cold fluid 1 increase with increasing flow rate of cold fluid 1, while the heat transfer rate of cold fluid 2 slightly decreases. That is, increasing flow rate of cold fluid 1 will reduce the heat transfer rate of the other side. When the flow rate of cold fluid 1 is relatively high, cold fluid 1 in the outlet is in two-phase state, as shown in Fig.11. Therefore to ensure that cold fluid 1 is superheated in the outlet, the flow rate of cold fluid 1 should be lower than a certain value, which is $0.033 \mathrm{~kg} \mathrm{~s}^{-1}$ in this study.

The heat transfer rate and outlet temperature varied with the flow rate of cold fluid 2 (air) are shown in Fig. 12 and Fig. 13, respectively. The heat transfer rates of the hot fluid and air increase with increasing air flow rate, while the heat transfer rate of cold fluid 1 slightly decreases. That is, increasing air flow rate will reduce the heat transfer rate of the fluid inside the inner tube. Cold fluid 1 is always superheated when the air flow rate is varied from 0 to $2.24 \mathrm{~m}^{3} \mathrm{~s}^{-1}$, which is quite a wide range, thus air flow rate can be adjusted freely according to demand of this system.

The heat transfer rate and outlet temperature varied with the inlet pressure of the hot fluid are shown in Fig. 14 and Fig. 15, respectively. With increasing inlet pressure of the hot fluid, the temperature differences between the hot fluid and the other two fluids increase therefore the heat transfer rates of all the three fluids increase, while the increase of cold fluid 1 is not as obvious as cold fluid 2 (air), due to superheated occurs in its outlet. When the inlet pressure of the hot fluid is relatively low, cold fluid 1 in the outlet is in two-phase state. To ensure that cold fluid 1 is superheated in the 
outlet, the inlet pressure of the hot fluid should be higher than a certain value, which is $0.801 \mathrm{MPa}$ in this study.

The heat transfer rate and outlet temperature varied with the inlet pressure of cold fluid 1 are shown in Fig. 16 and Fig. 17, respectively. With increasing inlet pressure of cold fluid 1, the temperature difference between the hot fluid and cold fluid 1 decreases therefore the heat transfer rates of the hot fluid and cold fluid 1 decrease, while the heat transfer rate of cold fluid 2 (air) slightly increases. When the inlet pressure of cold fluid 1 is relatively high, cold fluid 1 in the outlet is in twophase state. To ensure that cold fluid 1 is superheated in the outlet, the inlet pressure of cold fluid 1 should be lower than a certain value, which is $0.638 \mathrm{MPa}$ in this study.

The heat transfer rate and outlet temperature varied with the inlet temperature of cold fluid 2 (air) are shown in Fig. 18 and Fig. 19, respectively. With increasing air inlet temperature, the temperature difference between the hot fluid and air decreases therefore the heat transfer rate of the airside decreases. Meanwhile, the heat transfer rate of the other side increases. When the air inlet temperature is relatively low, cold fluid 1 in the outlet is in two-phase state, as shown in Fig.19. To ensure that cold fluid 1 is superheated in the outlet, air inlet temperature should be higher than $10{ }^{\circ} \mathrm{C}$ in this study. While, it should not be higher than the temperature of the hot fluid to maintain free cooling effect.

\section{Conclusions}

This study mainly focuses on three-fluid heat exchangers for application in hybrid source HVAC\&R systems. A distributed-parameter model of fin-tube threefluid heat exchanger is built and validated by experimental data. The performance of different geometric structures and working conditions is investigated based on the demand of ISMT, a new type of hybrid source HVAC\&R system. The main results 
are summarized as follows:

1) Circuit arrangement type has significant effect on the performance of fin-tube three-fluid heat exchanger. The optimal type with appropriate circuit number is achieved. The heat transfer rate increases with increasing inner tube diameter and it is fixed at $6.0 \mathrm{~mm}$ considering manufacture.

2) The heat transfer rates of the three fluids all increase with increasing flow rate of the hot fluid. To ensure that cold fluid 1 is superheated, flow rate of the hot fluid should be higher than a certain value, which is $0.044 \mathrm{~kg} \mathrm{~s}^{-1}$ in this study. Increasing flow rate of cold fluid 1 or cold fluid 2 (air) will improve the heat transfer rate of the hot fluid (total heat transfer rate) and its own side, while reduce the heat transfer rate of the other side. To ensure that cold fluid 1 is superheated, the flow rate of cold fluid 1 should be lower than a certain value, which is $0.033 \mathrm{~kg} \mathrm{~s}^{-1}$ in this study. However, air flow rate can be adjusted freely according to demand of application.

3) Increasing inlet pressure of the hot fluid will improve the heat transfer rates of all the three fluids. While, increasing inlet pressure of cold fluid 1 will reduce the heat transfer rate of the hot fluid and its own side, while improve that of the other side. To ensure that cold fluid 1 is superheated in the outlet, the inlet pressure of the hot fluid should be higher than a certain value, which is $0.801 \mathrm{MPa}$ in this study, and the inlet pressure of cold fluid 1 should be lower than a certain value, which is $0.638 \mathrm{MPa}$ in this study.

4) With increasing inlet temperature of cold fluid 2 (air), the heat transfer rate of the hot fluid and airside decreases while the heat transfer rate of the other side increases. To ensure that cold fluid 1 is superheated, air inlet temperature should be higher than $10{ }^{\circ} \mathrm{C}$ in this study.

\section{Acknowledgements}


The authors gratefully acknowledge the financial supports from Key

International Program of Chinese Academy of Sciences (CAS-DOE,

\section{A1111KYSB20150014).}

\section{References}

[1] US Department of Energy (DOE), 2010 Buildings Energy Data Book, 2011.

[2] Q. Qi, S. Deng, Y. Jiang, A simulation study on a solar heat pump heating system with seasonal latent heat storage, Sol. Energy 82 (2008) 669-675.

[3] H. Caliskan, I. Dincer, A. Hepbasli, Energy, exergy and sustainability analyses of hybrid renewable energy based hydrogen and electricity production and storage systems: Modeling and case study, Appl. Therm. Eng. 61 (2013) 784-798.

[4] X. Chen, L. Lu, H. Yang, Long term operation of a solar assisted ground coupled heat pump system for space heating and domestic hot water, Energy Build. 43 (2011) $1835-1844$.

[5] A.M. Elzahzby, A.E. Kabeel, M.M. Bassuoni, M. Abdelgaied, Effect of intercooling on the performance and economics of a solar energy assisted hybrid air conditioning system with six stages one-rotor desiccant wheel, Energy Convers. Manage. 78 (2014) 882-896.

[6] K.J. Chua, S.K. Chou, W.M. Wang, Advances in heat pump systems: a review, Appl. Energy 87 (2010) 3611-3624.

[7] O. Ozgener, Use of solar assisted geothermal heat pump and small wind turbine systems for heating agricultural and residential buildings, Energy 35 (2010) 262-268. [8] G. Xu, X. Zhang, S. Deng, A simulation study on the operating performance of a solar-air source heat pump water heater, Appl. Therm. Eng. 26 (2006) 1257-1265. [9] S. Li, S. Li, X. Zhang, Simulation research of a hybrid heat source heat pump using R134a,R744 instead of R22 for domestic water heating in residential buildings, 
Energy Build. 91 (2015) 57-64.

[10] H. Zhang, S. Shao, H. Xu, H. Zou, C. Tian, Free cooling of data centers: A review, Renew. Sustain. Energy Rev. 35 (2014) 171-182.

[11] L. Han, W. Shi, B. Wang, P. Zhang, X. Li, Development of an integrated air conditioner with thermosyphon and the application in mobile phone base station, Int. J. Refrig. 36 (2013) 58-69.

[12] H. Tian, Z. He, Z. Li, A combined cooling solution for high heat density data centers using multi-stage heat pipe loops, Energy Build. 94 (2015) 177-188.

[13] R.M. Lazzarin, Dual source heat pump systems: Operation and performance, Energy Build. 52 (2012) 77-85.

[14] S. Shao, Simulation of Complex Fluid Networks, Beijing, China: Tsinghua University, 2005 (in Chinese).

[15] J.S. Lee, K.S. Song, J.H. Ahn, Y. Kim, Comparison on the transient cooling performances of hybrid ground-source heat pumps with various flow loop configurations, Energy 82 (2015) 678-685.

[16] V. Krishna, P.G. Hegde, N. Subramanian, K.N. Seetharamu, Effect of ambient heat-in-leak on the performance of a three fluid heat exchanger, for cryogenic applications, using finite element method, Int. J. Heat Mass Transf. 55 (2012) 54595470.

[17] L. Malinowski, S. Bielski, Transient temperature field in a parallel-flow threefluid heat exchanger with the thermal capacitance of the walls and the longitudinal walls conduction, Appl. Therm. Eng. 29 (2009) 877-883.

[18] M. Zhao, Y. Li, New integral-mean temperature difference model for thermal design and simulation of parallel three-fluid heat exchanger, Int. J. Therm. Sci. 59 (2012) 203-213. 
[19] S.K. Singh, M. Mishra, P.K. Jha, Transient behavior of co-current parallel flow three-fluid heat exchanger, Int. Commun. Heat Mass Transf. 52 (2014) 46-50.

[20] T.B. Morley, Exchange of heat between three fluids, Engineer 155 (1933) 314.

[21] S. Bielski, L. Malinowski, An analytical method for determining transient temperature field in a parallel-flow three-fluid heat exchanger, Int. Commun. Heat Mass Transf. 32 (2005) 1034-1044.

[22] N.H. Saeid, K.N. Seetharamu, Finite element analysis for co-current and countercurrent parallel flow three-fluid heat exchanger, Int. J. Numer. Methods Heat Fluid Flow 16 (2006) 324-337.

[23] V. Krishna, S. Spoorthi, P.G. Hegde, K.N. Seetharamu, Effect of longitudinal wall conduction on the performance of a three-fluid cryogenic heat exchanger with three thermal communications, Int. J. Heat Mass Transf. 62 (2013) 567-577.

[24] D.F. Ruan, X.F. Yuan, S.Y. Wu, Y.R. Li, Exergy effectiveness analysis of threefluid heat exchanger, J. Supercond. Nov. Magn. 23 (2010) 1127-1131.

[25] D.F. Ruan, X.F. Yuan, Y.R. Li, S.Y. Wu, Entropy generation analysis of parallel and counter-flow three-fluid heat exchangers with three thermal communications, J. Non-Equil. Thermodyn. 36 (2011) 141-154.

[26] P. Yuan, H.S. Kou, The effect of longitudinal wall conduction in a three-fluid crossflow heat exchanger, Numer. Heat Transf. A. - Appl. 34 (1998) 135-150.

[27] P. Yuan, H.S. Kou, The comparison of longitudinal wall conduction effect on the crossflow heat exchangers including three fluid streams with different arrangements, Appl. Therm. Eng. 21 (2001) 1891-1907.

[28] P. Yuan, Effect of inlet flow maldistribution on the thermal performance of a three-fluid cross flow heat exchanger, Int. J. Heat Mass Transf. 46 (2003) 3777-3787. [29] D. Shrivastava, T.A. Ameel, Three-fluid heat exchangers with three thermal 
communications. Part A: general mathematical model, Int. J. Heat Mass Transf. 47 (2004) 3855-3865.

[30] D. Shrivastava, T.A. Ameel, Three-fluid heat exchangers with three thermal communications. Part B: effectiveness evaluation, Int. J. Heat Mass Transf. 47 (2004) $3867-3875$.

[31] Y. Liu, J. Ma, G. Zhou, The coupling performance of a solar-air heat pump, Proced. Eng. 15 (2011) 4058 - 4062.

[32] H. Zhang, S. Shao, H. Xu, H. Zou, C. Tian, Integrated system of mechanical refrigeration and thermosyphon for free cooling of data centers, Appl. Therm. Eng. 75 (2015) 185-192.

[33] S.G. Kandlikar, A general correlation for saturated two-phase flow boiling heat transfer inside horizontal and vertical tubes, J. Heat Transf. 112 (1990) 219-228.

[34] M. Shah, A general correlation for heat transfer during film condensation inside pipes, Int. J. Heat Mass Transf. 22 (1979) 547-556.

[35] F.W. Dittus, L.M.K. Boelter, Heat transfer in automobile radiators of the tubular type, U. Cal. Publ. Eng. 2 (1930) 443-461.

[36] J.Z. Yu, Heat Exchanger Design, Beihang University Press, Beijing, 2005 (in Chinese).

[37] R. Lockhart, R. Martinelli, Proposed correlation of data for isothermal two-phase, two-component flow in pipes, Chem. Eng. Progr. 45 (1949) 39-48.

[38] S.R. Jing, M.Y. Zhang, Fluid dynamics, Xi'an Jiaotong University Press, Xi'an, 2001 (in Chinese).

[39] Nist, NIST Reference Fluid Thermodynamic and Transport Properties Version 8.0, 2007. 


\section{Figure Captions}

Fig. 1. Structure of fin-tube three-fluid heat exchanger.

Fig. 2. Schematic diagram of the ISMT [32].

Fig. 3. Flow arrangement of one tube circuit.

Fig. 4. Flow chart of simulation.

Fig. 5. Comparison of calculated and experimental values of heat transfer rate.

Fig. 6. Three different circuit arrangement types.

Fig. 7. Heat transfer rate of different structures.

Fig. 8. Heat transfer rate varied with flow rate of hot fluid.

Fig. 9. Outlet temperature varied with flow rate of hot fluid.

Fig. 10. Heat transfer rate varied with flow rate of cold fluid 1.

Fig. 11. Outlet temperature varied with flow rate of cold fluid 1.

Fig. 12. Heat transfer rate varied with flow rate of cold fluid 2 (air).

Fig. 13. Outlet temperature varied with flow rate of cold fluid 2 (air).

Fig. 14. Heat transfer rate varied with inlet pressure of hot fluid.

Fig. 15. Outlet temperature varied with inlet pressure of hot fluid.

Fig. 16. Heat transfer rate varied with inlet pressure of cold fluid 1.

Fig. 17. Outlet temperature varied with inlet pressure of cold fluid 1.

Fig. 18. Heat transfer rate varied with inlet temperature of cold fluid 2 (air).

Fig. 19. Outlet temperature varied with inlet temperature of cold fluid 2 (air). 


\section{Table Captions}

Table 1. Heat transfer and pressure drop correlations used for simulation.

Table 2. Working condition for structure investigation.

Table 3. Geometric parameters of three-fluid heat exchanger.

Table 4. Working conditions for performance investigation. 
Table 1 Heat transfer and pressure drop correlations used for simulation

\begin{tabular}{cc}
\hline Item & Correlation \\
\hline Evaporation heat transfer & Kandlikar [33] \\
Condensation heat transfer & Shah [34] \\
Single-phase heat transfer & Dittus and Boelter [35] \\
Airside heat transfer & Yu [36] \\
Two-phase friction pressure drop & Lockhart and Martinelli [37] \\
Single-phase friction pressure drop & Blasius [38]
\end{tabular}


Table 2 Working condition for structure investigation

\begin{tabular}{|c|c|}
\hline Parameter & Value \\
\hline Inlet enthalpy of the hot fluid $\left(\mathrm{kJ} \mathrm{kg}^{-1}\right)$ & 392.3 \\
\hline Inlet pressure of the hot fluid (MPa) & 0.8207 \\
\hline Mass flow rate of the hot fluid $\left(\mathrm{kg} \mathrm{s}^{-1}\right)$ & 0.0462 \\
\hline Outlet enthalpy of cold fluid $1\left(\mathrm{~kJ} \mathrm{~kg}^{-1}\right)$ & 409.4 \\
\hline Outlet pressure of cold fluid $1(\mathrm{MPa})$ & 0.6089 \\
\hline Mass flow rate of cold fluid $1\left(\mathrm{~kg} \mathrm{~s}^{-1}\right)$ & 0.031 \\
\hline Temperature of cold fluid 2 (air) $\left({ }^{\circ} \mathrm{C}\right)$ & 12.0 \\
\hline Relative humidity of cold fluid 2 (air) & $50 \%$ \\
\hline Volume flow rate of cold fluid 2 (air) $\left(\mathrm{m}^{3} \mathrm{~s}^{-1}\right)$ & 1.114 \\
\hline Type of cold fluid 1 and the hot fluid & $\mathrm{R} 22$ \\
\hline
\end{tabular}


Table 3 Geometric parameters of three-fluid heat exchanger

\begin{tabular}{cccc}
\hline Parameter & Value & Parameter & Value \\
\hline Tube length $(\mathrm{mm})$ & 700 & Number of rows & 2 \\
Inner tube outside diameter $(\mathrm{mm})$ & $5.2-6.4$ & Tube pitch $(\mathrm{mm})$ & 25.0 \\
Inner tube wall thickness $(\mathrm{mm})$ & 0.25 & Row pitch $(\mathrm{mm})$ & 21.65 \\
Outer tube outside diameter $(\mathrm{mm})$ & 9.52 & Fin pitch $(\mathrm{mm})$ & 1.5 \\
Outer tube wall thickness $(\mathrm{mm})$ & 0.26 & Fin thickness $(\mathrm{mm})$ & 0.12 \\
\hline
\end{tabular}


Table 4 Working conditions for performance investigation

\begin{tabular}{|c|c|c|}
\hline Parameter & Base line & Variation range \\
\hline Inlet enthalpy of the hot fluid $\left(\mathrm{kJ} \mathrm{kg}^{-1}\right)$ & 392.3 & -- \\
\hline Inlet pressure of the hot fluid (MPa) & 0.8207 & $0.79-0.84$ \\
\hline Mass flow rate of the hot fluid $\left(\mathrm{kg} \mathrm{s}^{-1}\right)$ & 0.0462 & $0.037-0.066$ \\
\hline Inlet enthalpy of cold fluid $1\left(\mathrm{~kJ} \mathrm{~kg}^{-1}\right)$ & 256.2 & -- \\
\hline Inlet pressure of cold fluid $1(\mathrm{MPa})$ & 0.6282 & $0.60-0.65$ \\
\hline Mass flow rate of cold fluid $1\left(\mathrm{~kg} \mathrm{~s}^{-1}\right)$ & 0.031 & $0.026-0.035$ \\
\hline Inlet temperature of cold fluid 2 (air) $\left({ }^{\circ} \mathrm{C}\right)$ & 12.0 & $8.0-16.0$ \\
\hline Relative humidity of cold fluid 2 (air) & $50 \%$ & -- \\
\hline Volume flow rate of cold fluid 2 (air) $\left(\mathrm{m}^{3} \mathrm{~s}^{-1}\right)$ & 1.114 & $0-2.24$ \\
\hline
\end{tabular}


Fins

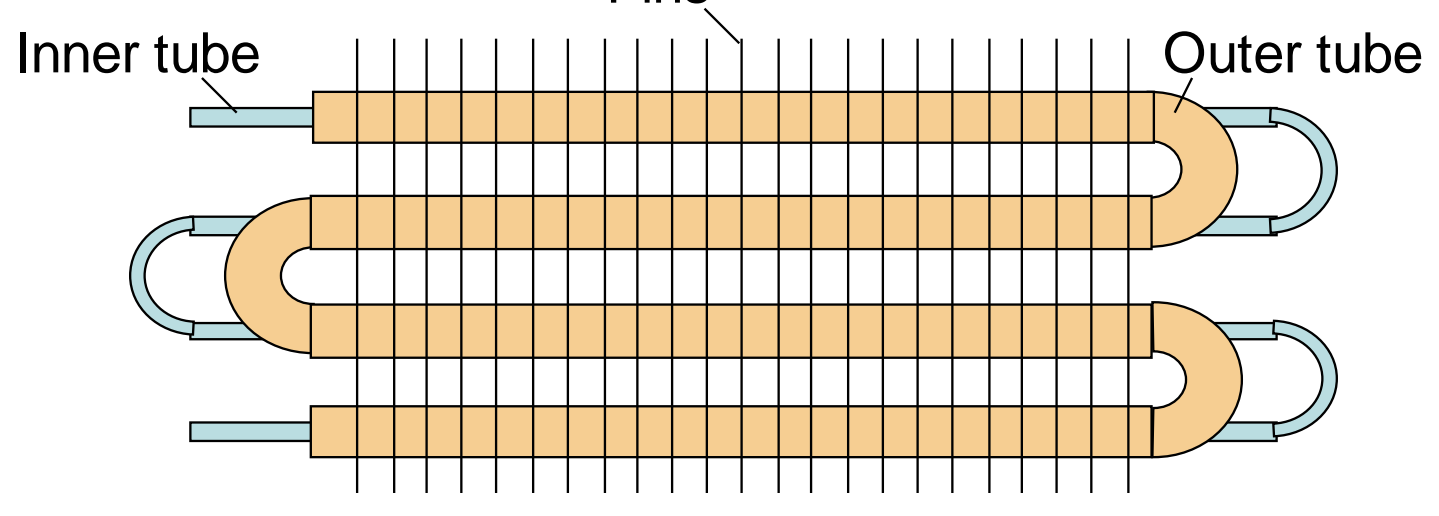

Fig. 1 Structure of fin-tube three-fluid heat exchanger 


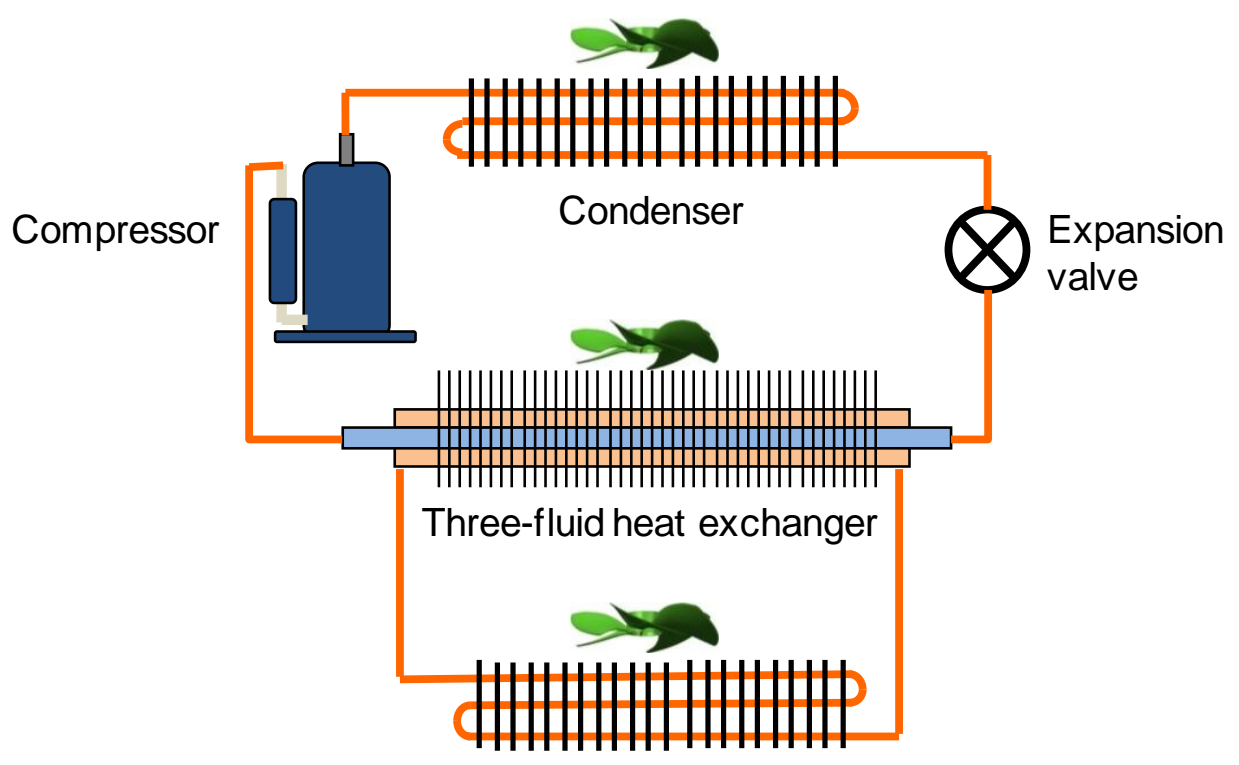

Evaporator

Fig. 2 Schematic diagram of the ISMT [32] 


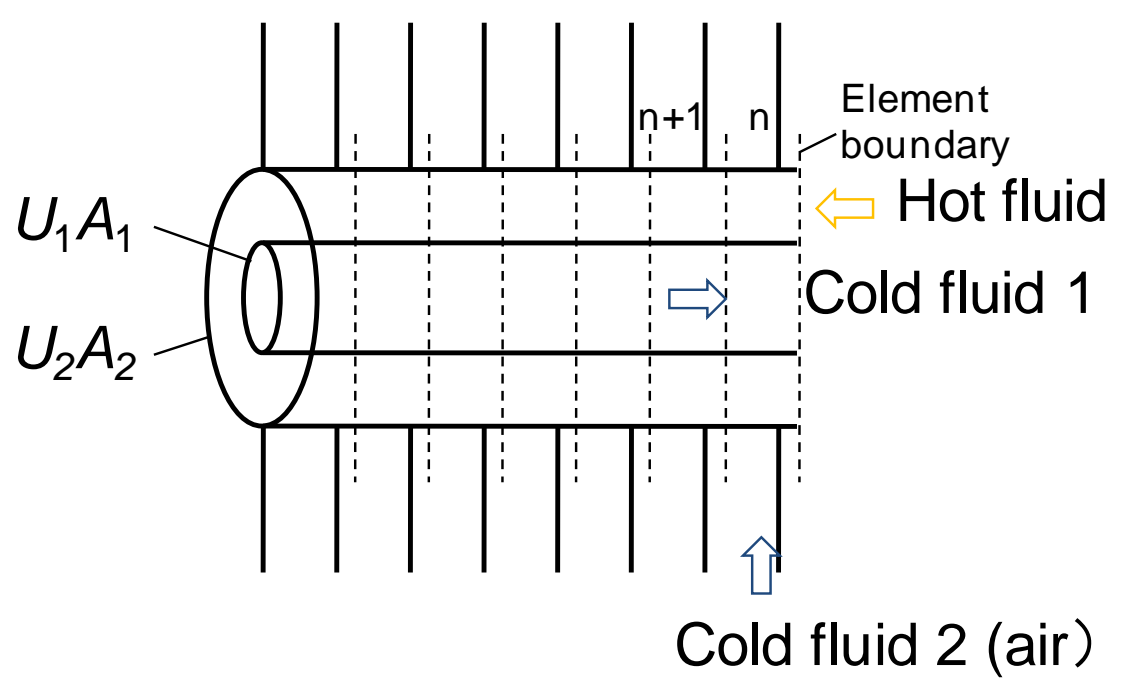

Fig. 3 Flow arrangement of one tube circuit 


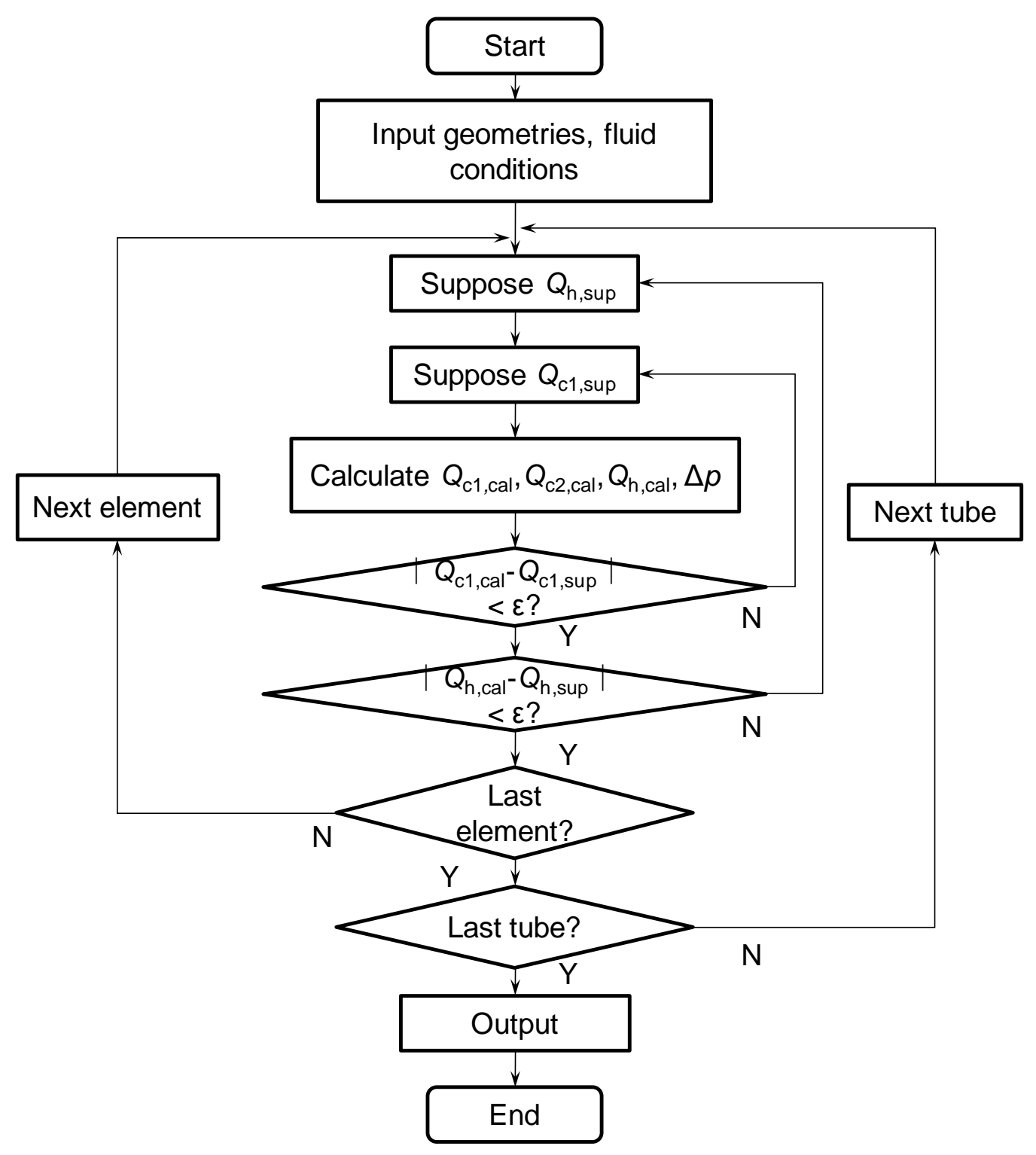

Fig. 4 Flow chart of simulation 


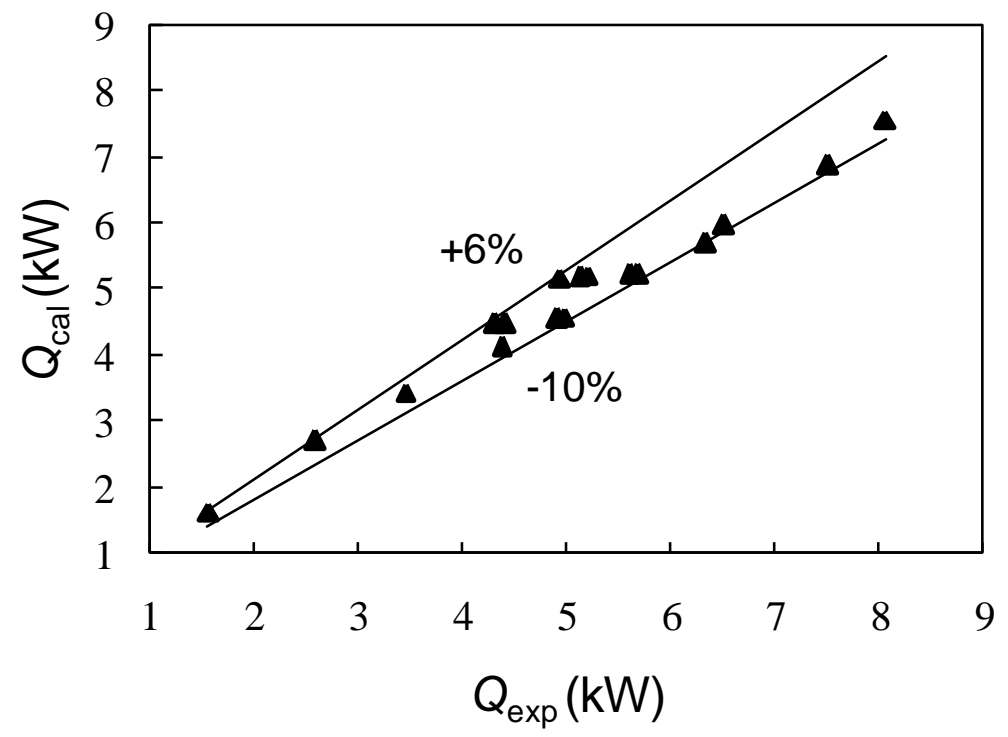

Fig. 5 Comparison of calculated and experimental values of heat transfer rate 

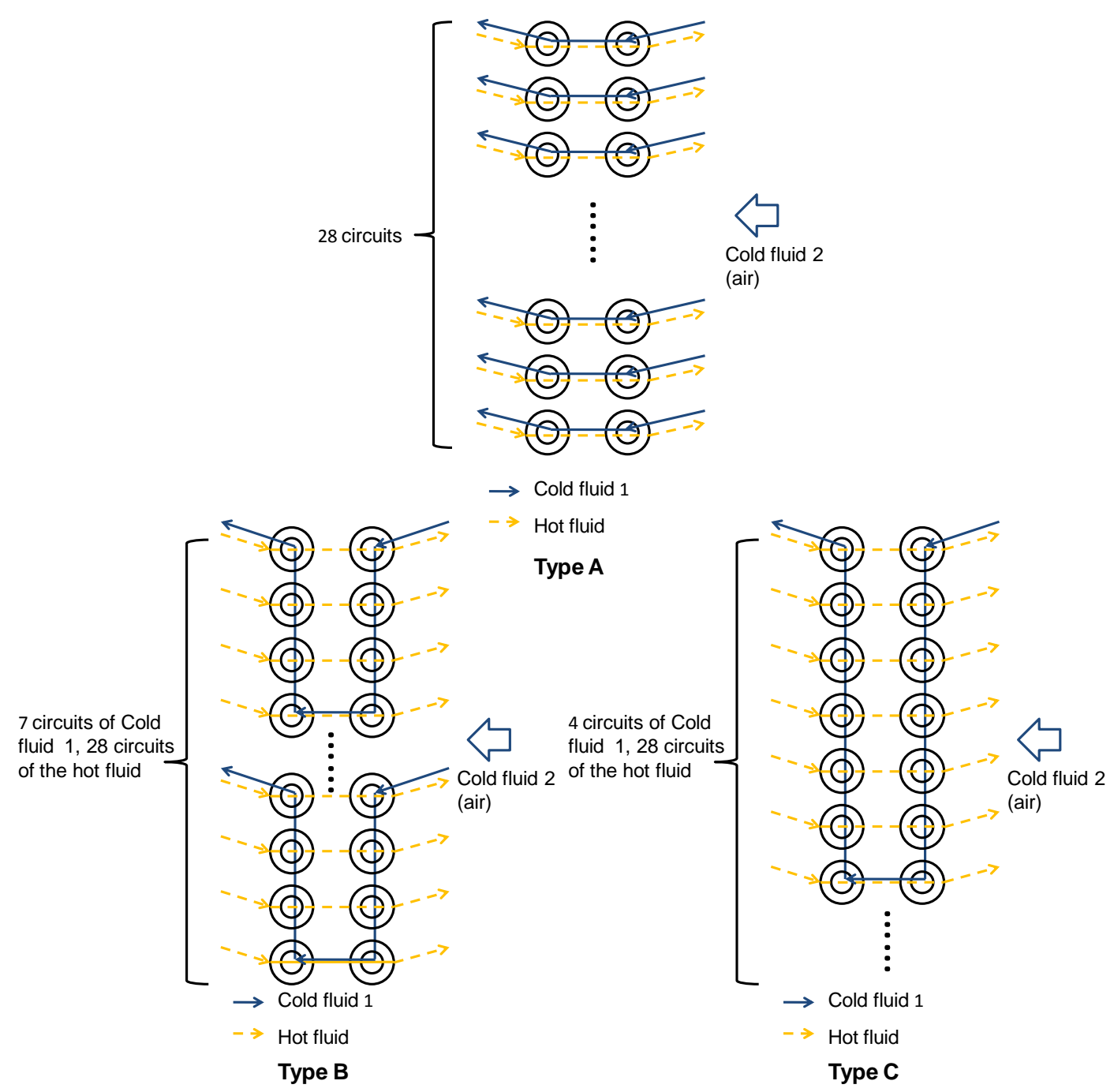

Fig. 6 Three different circuit arrangement types 


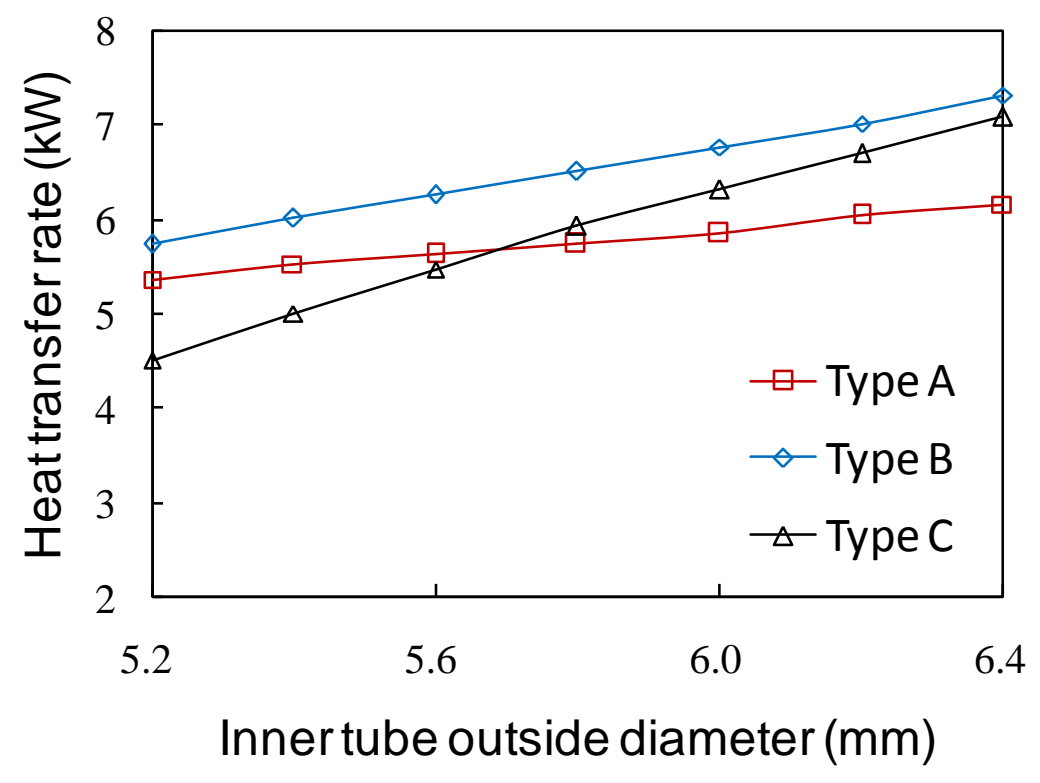

Fig. 7 Heat transfer rate of different structures 


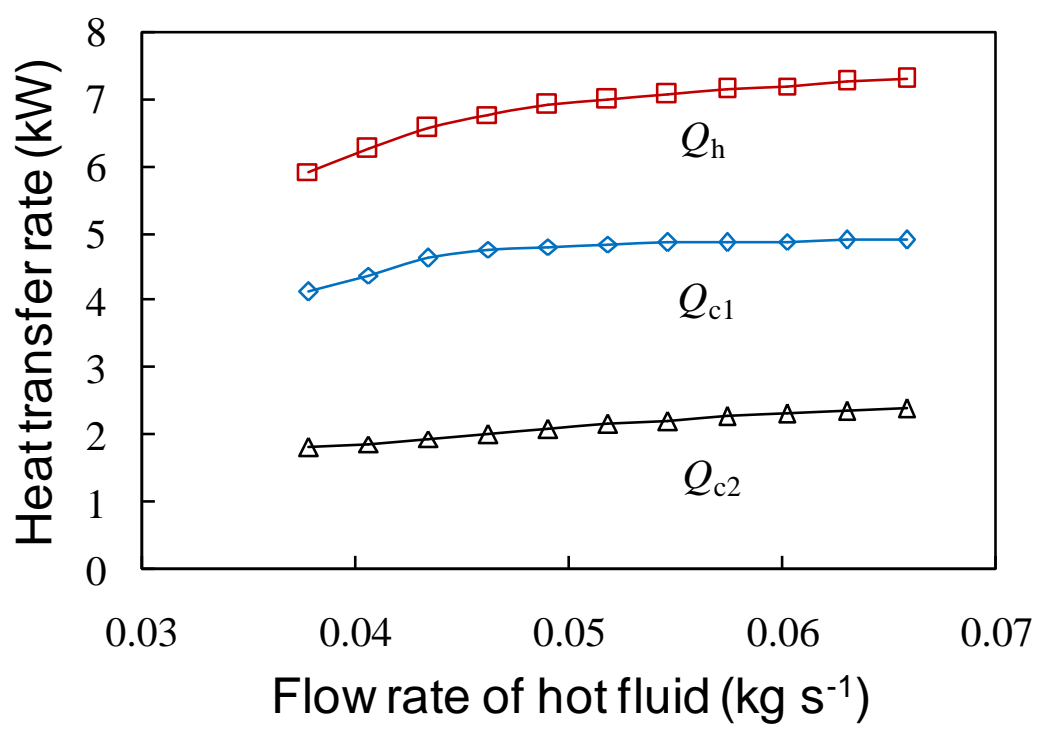

Fig. 8 Heat transfer rate varied with flow rate of hot fluid for $\dot{m}_{\mathrm{c} 1}=0.031 \mathrm{~kg} \mathrm{~s}^{-1}, \quad \dot{v}_{\mathrm{c} 2}=$ $1.114 \mathrm{~m}^{-3} \mathrm{~s}^{-1}, p_{\mathrm{h}, \mathrm{in}}=0.8207 \mathrm{MPa}, p_{\mathrm{c} 1, \mathrm{in}}=0.6282 \mathrm{MPa}, T_{\mathrm{c} 2, \mathrm{in}}=12.0^{\circ} \mathrm{C}$ 


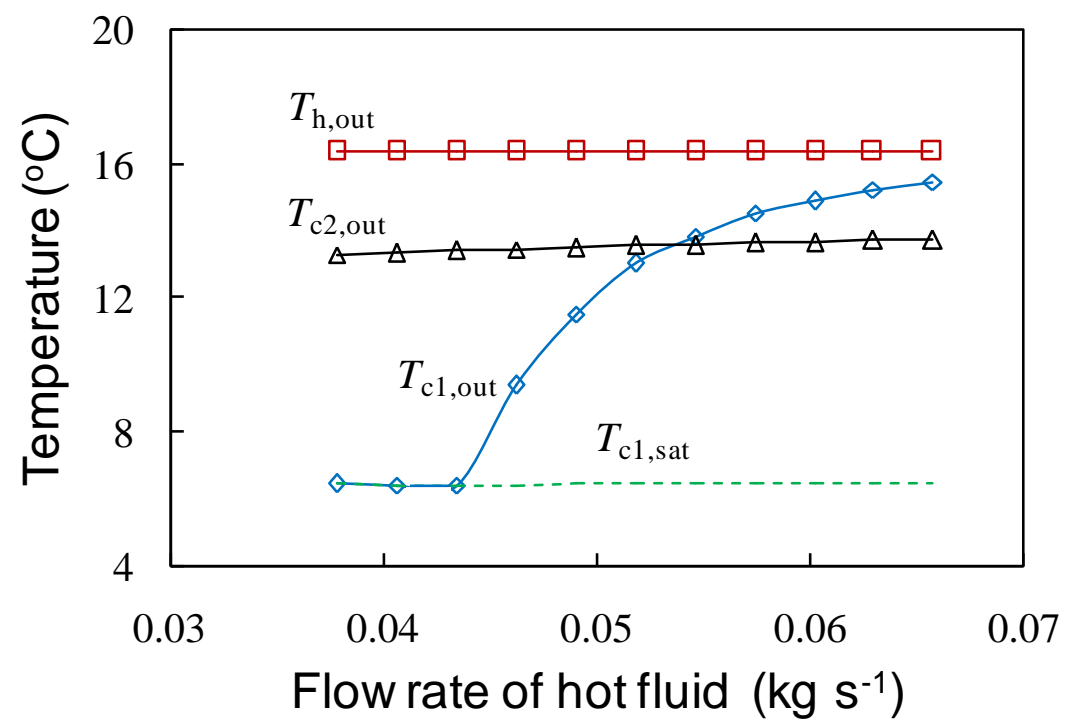

Fig. 9 Outlet temperature varied with flow rate of hot fluid for $\dot{m}_{\mathrm{cl}}=0.031 \mathrm{~kg} \mathrm{~s}^{-1}$,

$$
\dot{v}_{\mathrm{c} 2}=1.114 \mathrm{~m}^{-3} \mathrm{~s}^{-1}, p_{\mathrm{h}, \mathrm{in}}=0.8207 \mathrm{MPa}, p_{\mathrm{c} 1, \mathrm{in}}=0.6282 \mathrm{MPa}, T_{\mathrm{c} 2, \mathrm{in}}=12.0^{\circ} \mathrm{C}
$$




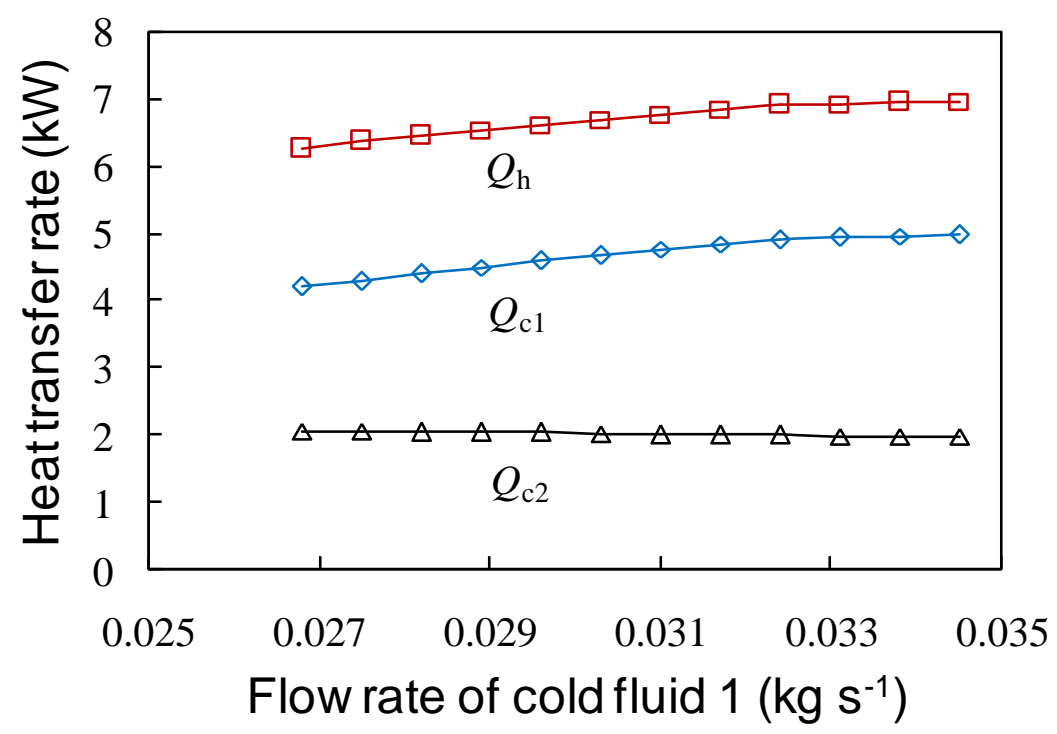

Fig. 10 Heat transfer rate varied with flow rate of cold fluid 1 for $\dot{m}_{\mathrm{h}}=0.0462 \mathrm{~kg}$ $\mathrm{s}^{-1}, \quad \dot{v}_{\mathrm{c} 2}=1.114 \mathrm{~m}^{-3} \mathrm{~s}^{-1}, p_{\mathrm{h}, \text { in }}=0.8207 \mathrm{MPa}, p_{\mathrm{c} 1, \mathrm{in}}=0.6282 \mathrm{MPa}, T_{\mathrm{c} 2, \mathrm{in}}=12.0{ }^{\circ} \mathrm{C}$ 


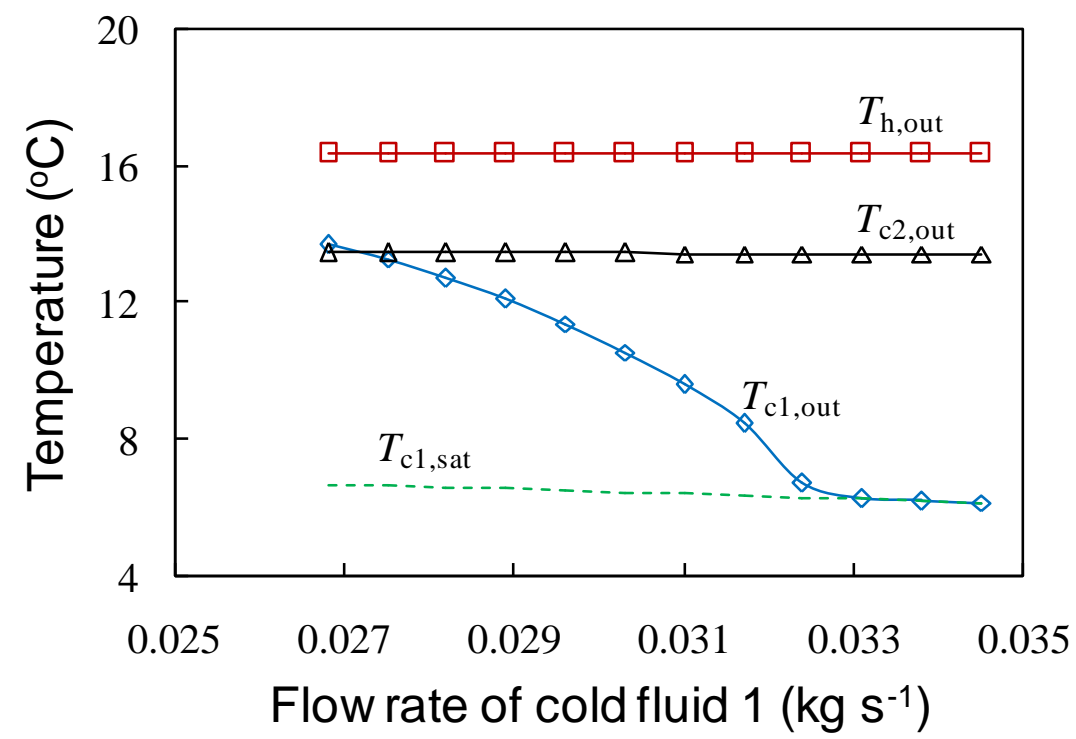

Fig. 11 Outlet temperature varied with flow rate of cold fluid 1 for $\dot{m}_{\mathrm{h}}=0.0462 \mathrm{~kg}$ $\mathrm{s}^{-1}, \quad \dot{v}_{\mathrm{c} 2}=1.114 \mathrm{~m}^{-3} \mathrm{~s}^{-1}, p_{\mathrm{h}, \mathrm{in}}=0.8207 \mathrm{MPa}, p_{\mathrm{c} 1, \mathrm{in}}=0.6282 \mathrm{MPa}, T_{\mathrm{c} 2, \mathrm{in}}=12.0^{\circ} \mathrm{C}$ 


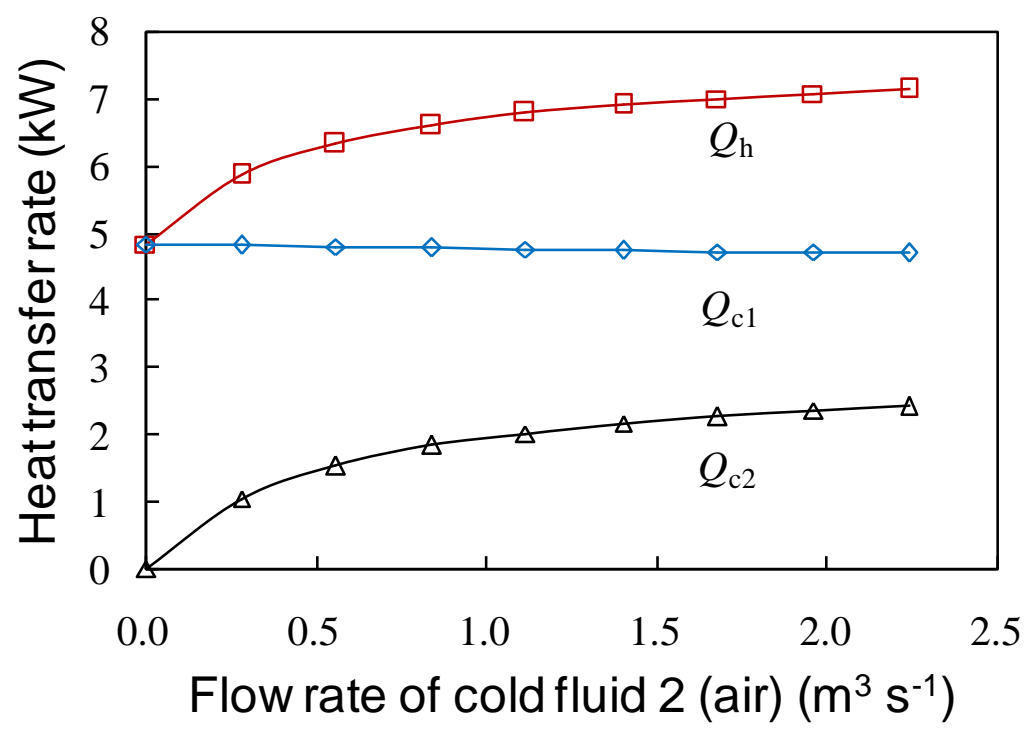

Fig. 12 Heat transfer rate varied with flow rate of cold fluid 2 (air) for $\dot{m}_{\mathrm{h}}=0.0462$ $\mathrm{kg} \mathrm{s}^{-1}, \quad \dot{m}_{\mathrm{c} 1}=0.031 \mathrm{~kg} \mathrm{~s}^{-1}, p_{\mathrm{h}, \mathrm{in}}=0.8207 \mathrm{MPa}, p_{\mathrm{c} 1, \mathrm{in}}=0.6282 \mathrm{MPa}, T_{\mathrm{c} 2, \mathrm{in}}=12.0^{\circ} \mathrm{C}$ 


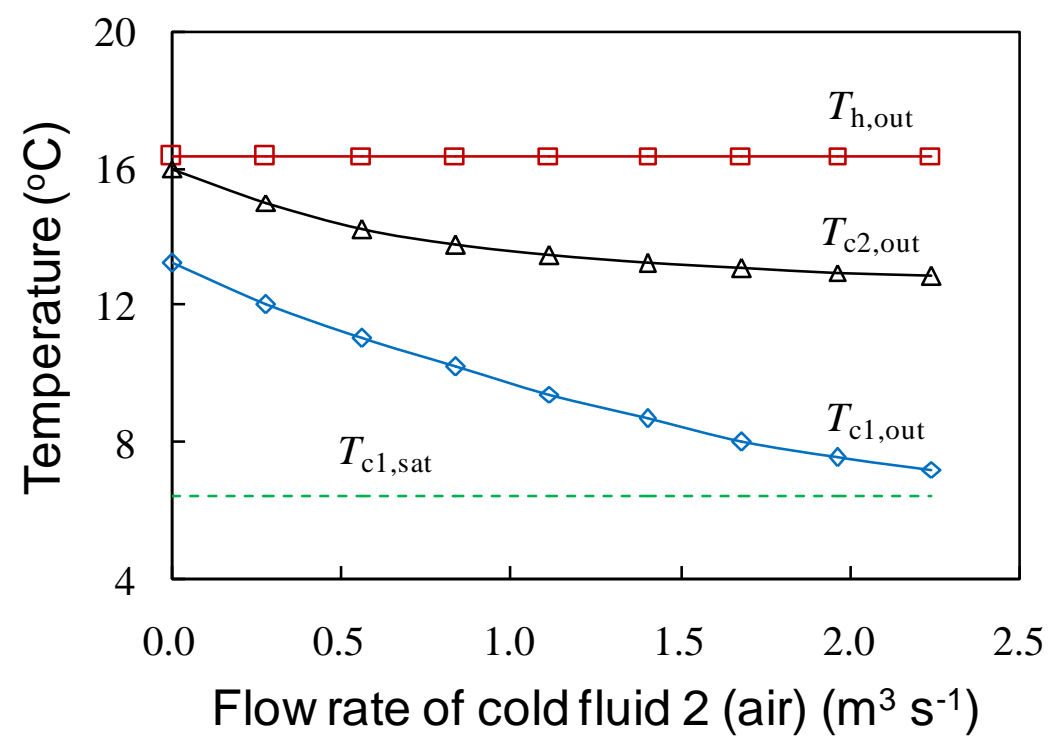

Fig. 13 Outlet temperature varied with flow rate of cold fluid 2 (air) for $\dot{m}_{\mathrm{h}}=0.0462$ $\mathrm{kg} \mathrm{s}^{-1}, \quad \dot{m}_{\mathrm{c} 1}=0.031 \mathrm{~kg} \mathrm{~s}^{-1}, p_{\mathrm{h}, \mathrm{in}}=0.8207 \mathrm{MPa}, p_{\mathrm{c} 1, \mathrm{in}}=0.6282 \mathrm{MPa}, T_{\mathrm{c} 2, \mathrm{in}}=12.0^{\circ} \mathrm{C}$ 


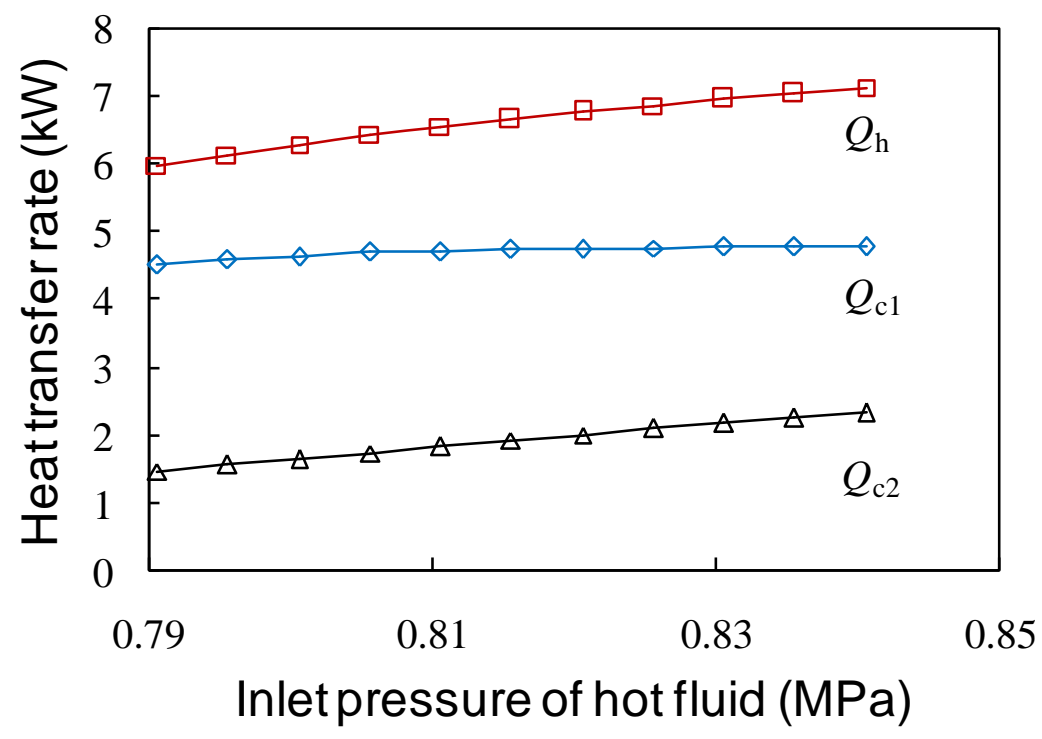

Fig. 14 Heat transfer rate varied with inlet pressure of hot fluid for $\dot{m}_{\mathrm{h}}=0.0462 \mathrm{~kg} \mathrm{~s}^{-1}$,

$$
\dot{m}_{\mathrm{c} 1}=0.031 \mathrm{~kg} \mathrm{~s}^{-1}, \quad \dot{v}_{\mathrm{c} 2}=1.114 \mathrm{~m}^{-3} \mathrm{~s}^{-1}, p_{\mathrm{c} 1, \text { in }}=0.6282 \mathrm{MPa}, T_{\mathrm{c} 2, \mathrm{in}}=12.0{ }^{\circ} \mathrm{C}
$$




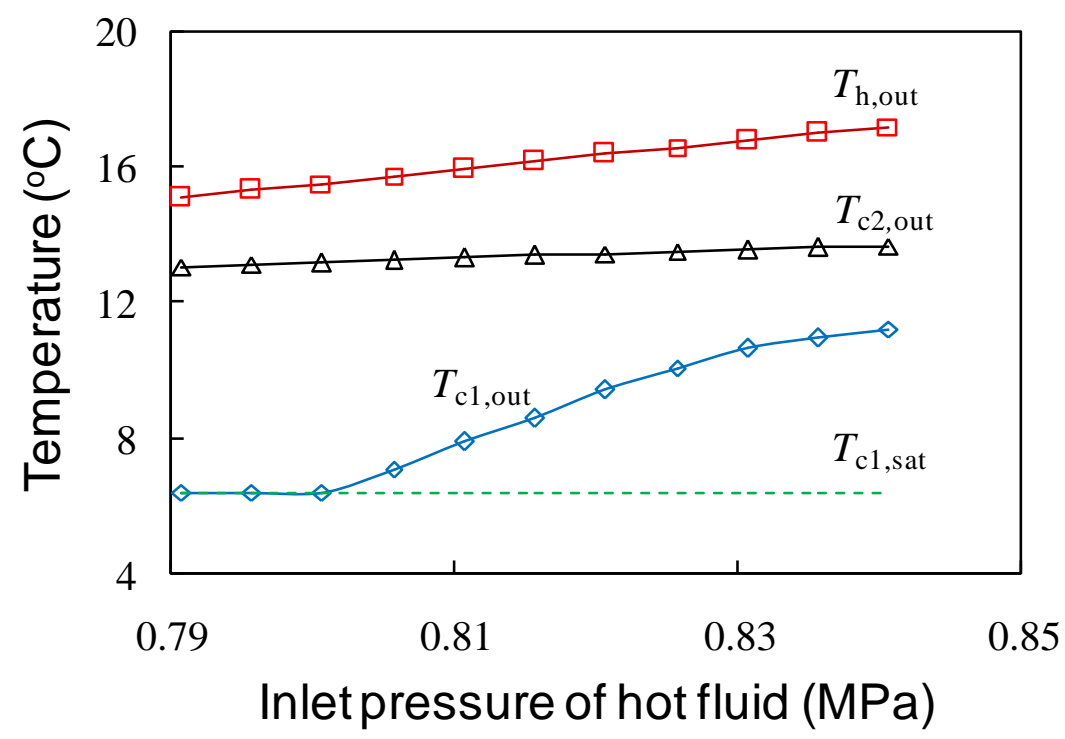

Fig. 15 Outlet temperature varied with inlet pressure of hot fluid for $\dot{m}_{\mathrm{h}}=0.0462 \mathrm{~kg}$ $\mathrm{s}^{-1}, \quad \dot{m}_{\mathrm{c} 1}=0.031 \mathrm{~kg} \mathrm{~s}^{-1}, \quad \dot{v}_{\mathrm{c} 2}=1.114 \mathrm{~m}^{-3} \mathrm{~s}^{-1}, p_{\mathrm{c} 1, \text { in }}=0.6282 \mathrm{MPa}, T_{\mathrm{c} 2, \mathrm{in}}=12.0{ }^{\circ} \mathrm{C}$ 


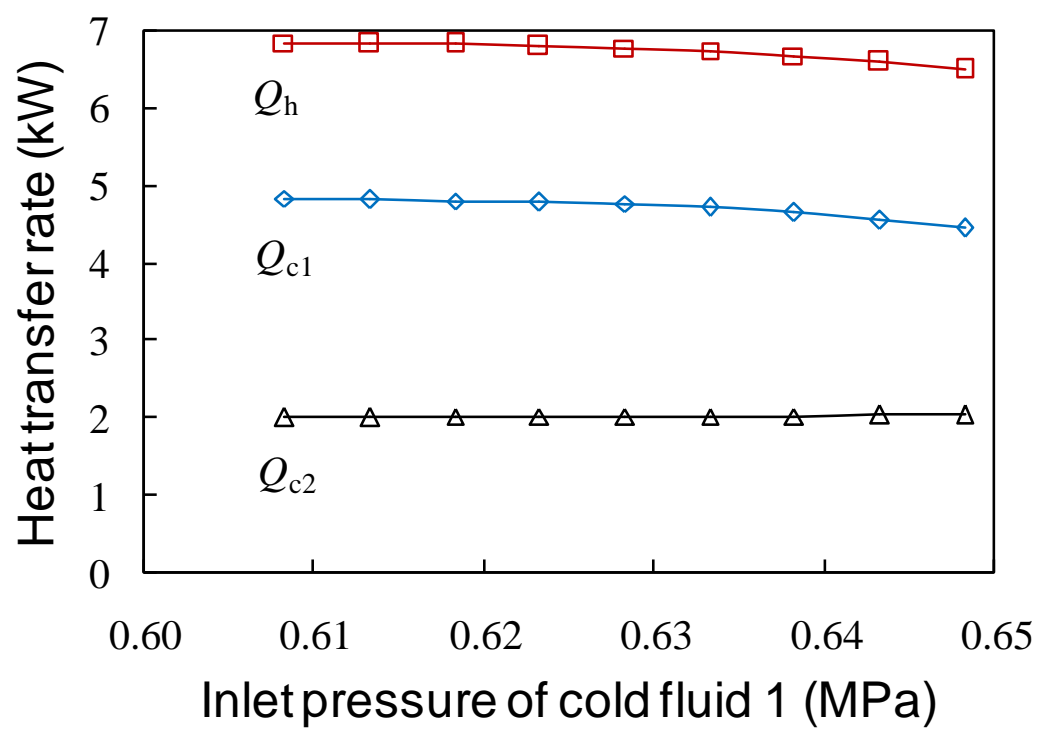

Fig. 16 Heat transfer rate varied with inlet pressure of cold fluid 1 for $\dot{m}_{\mathrm{h}}=0.0462 \mathrm{~kg}$ $\mathrm{s}^{-1}, \quad \dot{m}_{\mathrm{c} 1}=0.031 \mathrm{~kg} \mathrm{~s}^{-1}, \quad \dot{v}_{\mathrm{c} 2}=1.114 \mathrm{~m}^{-3} \mathrm{~s}^{-1}, p_{\mathrm{h}, \text { in }}=0.8207 \mathrm{MPa}, T_{\mathrm{c} 2, \mathrm{in}}=12.0{ }^{\circ} \mathrm{C}$ 


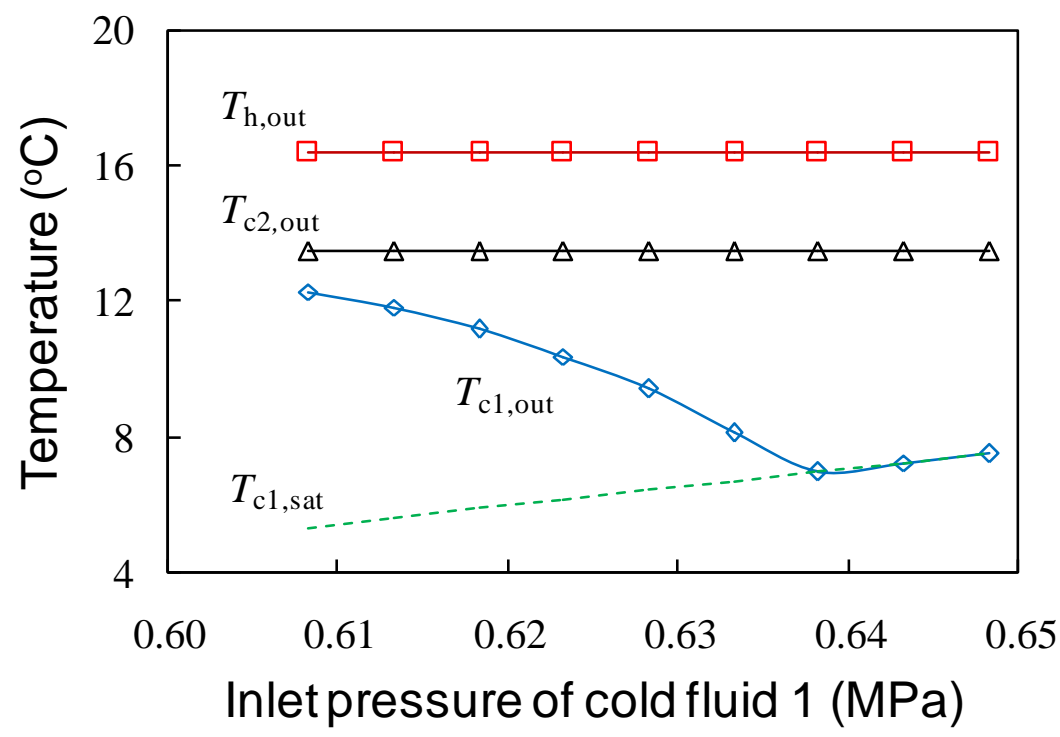

Fig. 17 Outlet temperature varied with inlet pressure of cold fluid 1 for $\dot{m}_{\mathrm{h}}=0.0462$ $\mathrm{kg} \mathrm{s}^{-1}, \quad \dot{m}_{\mathrm{c} 1}=0.031 \mathrm{~kg} \mathrm{~s}^{-1}, \quad \dot{v}_{\mathrm{c} 2}=1.114 \mathrm{~m}^{-3} \mathrm{~s}^{-1}, p_{\mathrm{h}, \text { in }}=0.8207 \mathrm{MPa}, T_{\mathrm{c} 2, \text { in }}=12.0{ }^{\circ} \mathrm{C}$ 


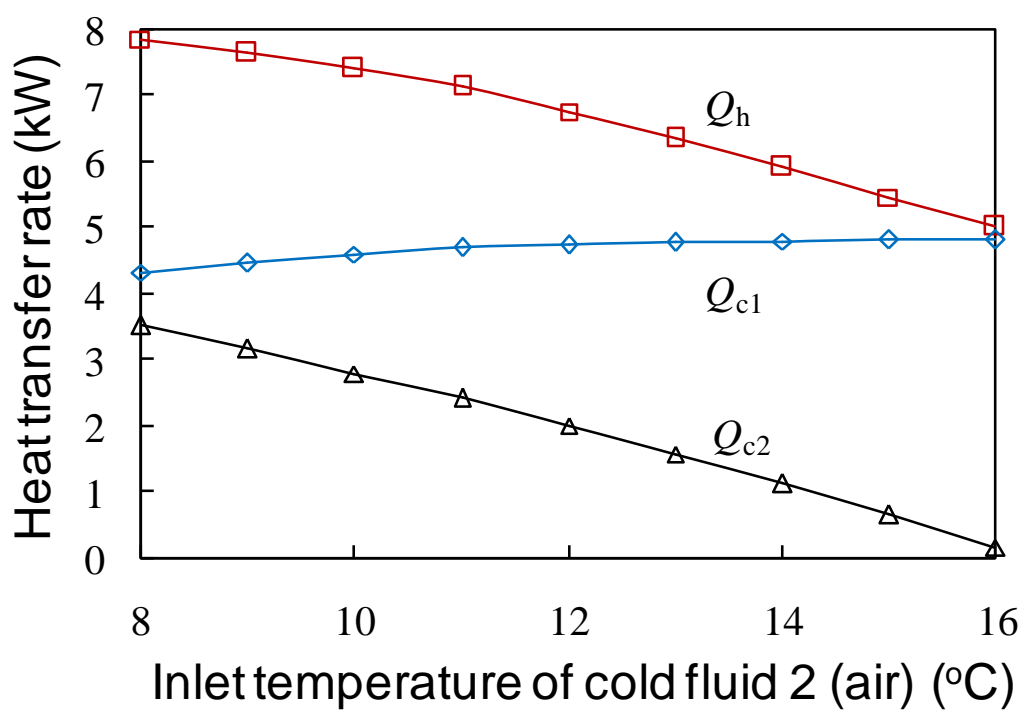

Fig. 18 Heat transfer rate varied with inlet temperature of cold fluid 2 (air) for $\dot{m}_{\mathrm{h}}=$ $0.0462 \mathrm{~kg} \mathrm{~s}^{-1}, \quad \dot{m}_{\mathrm{c} 1}=0.031 \mathrm{~kg} \mathrm{~s}^{-1}, \quad \dot{v}_{\mathrm{c} 2}=1.114 \mathrm{~m}^{-3} \mathrm{~s}^{-1}, p_{\mathrm{h}, \mathrm{in}}=0.8207 \mathrm{MPa}, p_{\mathrm{c} 1, \mathrm{in}}=0.6282$ $\mathrm{MPa}$ 


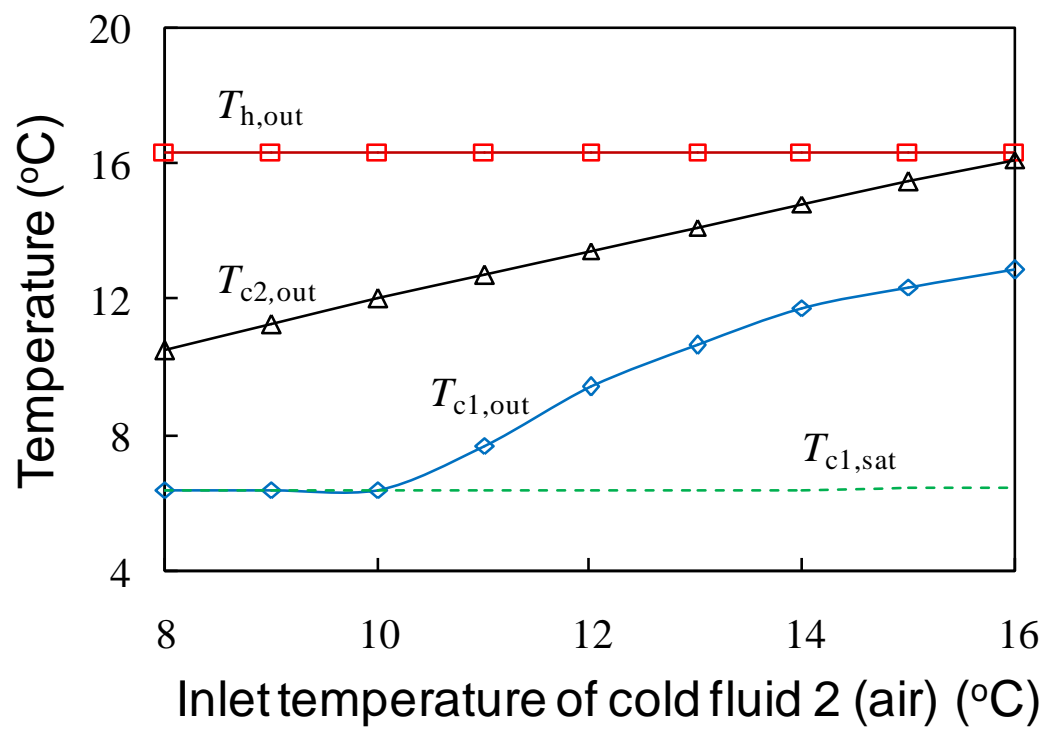

Fig. 19 Outlet temperature varied with inlet temperature of cold fluid 2 (air) for $\dot{m}_{\mathrm{h}}=$ $0.0462 \mathrm{~kg} \mathrm{~s}^{-1}, \quad \dot{m}_{\mathrm{c} 1}=0.031 \mathrm{~kg} \mathrm{~s}^{-1}, \quad \dot{v}_{\mathrm{c} 2}=1.114 \mathrm{~m}^{-3} \mathrm{~s}^{-1}, p_{\mathrm{h}, \mathrm{in}}=0.8207 \mathrm{MPa}, p_{\mathrm{c} 1, \mathrm{in}}=0.6282$ $\mathrm{MPa}$ 